\title{
МЕЖДИСЦИПЛИНАРНОЕ ВЗАИМОДЕЙСТВИЕ ЭНДОКРИНОЛОГА И ОНКОЛОГА ПРИ ГОРМОНАЛЬНОМ ЛЕЧЕНИИ МЕСТНО-РАСПРОСТРАНЕННОГО РАКА ПРЕДСТАТЕЛЬНОЙ ЖЕЛЕЗЫ АГОНИСТАМИ ЛЮТЕИНИЗИРУЮЩЕГО ГОРМОНА-РИЛИЗИНГ-ГОРМОНА
}

\author{
'Грицкевич Е.Ю., ' Демидова Т.Ю., ${ }^{2}$ Быстров А.А., ${ }^{3}$ Матуров М.Р.
}

\begin{abstract}
${ }^{1}$ Федеральное государственное автономное образовательное учреждение высшего образования «Российский национальный исследовательский медицинский университет имени Н.И. Пирогова» Министерства здравоохранения Российской Федерации, Москва

²Обособленное подразделение Центр амбулаторной помощи ГБУЗ «ГКБ имени Д.Д. Плетнева ДЗМ», Москва ${ }^{3}$ Государственное бюджетное учреждение здравоохранения города Москвы «Московская городская онкологическая больница №62 ДЗМ», Москва
\end{abstract}

Андроген-депривационная терапия (АДТ) является одной из важнейших в лечении распространенного и метастатического рака предстательной железы (РПЖ), поскольку РПЖ — гормонально зависимая опухоль. АДТ направлена на блокирование синтеза или действия андрогенов, которые стимулируют пролиферацию ткани предстательной железы путем двусторонней орхэктомии или использования лекарственных препаратов. Основными из используемых препаратов являются агонисты лютеинизирующего гормона-рилизинг гормона (аЛГРГ). Они способствуют увеличению продолжительности пациентов, снижают риск осложнений, ассоциированных с прогрессией РПЖ. Однако из-за достижения ятрогенного гипогонадизма возрастает вероятность осложнений, связанных уже с самой АДТ, в том числе и метаболических, которые ассоциируются с негативными кардиоваскулярными исходами.

ЦЕЛЬ: изучение нарушений углеводного и жирового обмена у пациентов с местно-распространенным РПЖ (рТ3NOMO) и биохимическим рецидивом, получавших лечение аЛГРГ на базе ГБУЗ «ГКБ им. Д.Д. Плетнева ДЗМ» с 2014 по 2019 гг.

МАТЕРИАЛЫ И МЕТОДЫ: данная работа представляет собой проспективное исследование. Для оценки метаболических нарушений производилось измерение окружности талии (ОТ), индекса массы тела (ИМТ), анализ уровня глюкозы плазмы натощак (ГПН), гликированного гемоглобина (НbА ${ }_{1 c}$, триглицеридов (ТГ), общего холестерина (ОХ) перед инициацией АДТ и через 3, 6 и 12 мес. после. Полученные данные обрабатывались в программе IBM SPSS Statistics 23.0.

РЕЗУЛЬТАТЫ: в исследование были включены 99 участников, средний возраст которых составил 69 лет (95\% доверительный интервал (ДИ): 61,5-79,2 лет). Парные сравнения оцениваемых параметров проводились с помощью анализа на межгрупповые различия с течением времени по данным модели повторных измерений (MANOVA). Были получены следующие средние значения исследуемых параметров исходно, через 3, 6 и 12 мес соответственно (в том числе в \% от базовых значений): ОТ, в см.:

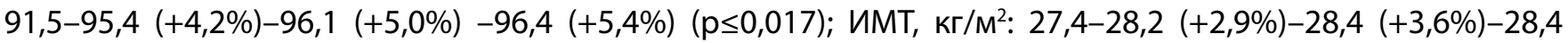
$(+3,6 \%)(\mathrm{p} \leq 0,004)$, кроме сравнения результатов за 6 и 12 мес. - p=0,995); ГПН, ммоль/л: 5,2-5,7 (+9,6\%)-5,8

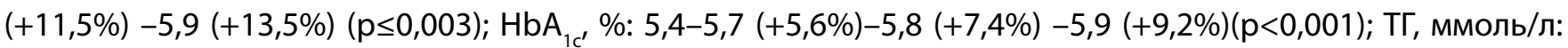

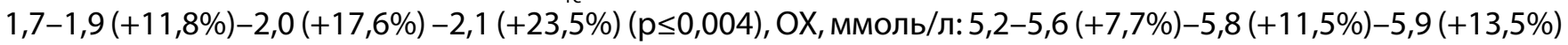
$(\mathrm{p}<0,001)$. Статистически значимые положительные корреляции выявлены между динамикой показателей ИМТ и ОТ ( $R=0,487, p<0,001)$, и ИМТ и $\mathrm{HbA}_{1 c}(R=0,245, p=0,015)$.

ВЫВОДЫ: у пациентов, получающих монотерапию аЛГРГ по поводу РПЖ в исследовании отмечалось увеличение ОТ, ИМТ, что коррелировало с развитием нарушений углеводного обмена, значимое изменение претерпели показатели липидного обмена. Наибольшее повышение изучаемых показателей происходило в первые три месяца терапии, после чего скорость их роста снизилась. Наиболее выражено изменялись ТГ крови. Согласно полученным результатам, может быть целесообразен контроль ОТ, ИМТ и, вероятно, некоторых показателей углеводного и липидного обмена через 3 и 12 мес. после начала АДТ для выявления ранних нарушений метаболизма и их коррекции, что возможно в условиях междисциплинарного взаимодействия онкологов и эндокринологов. Однако необходимо дальнейшее изучение метаболических осложнений АДТ и расширение доказательной базы для проверки полученных данных и разработки механизмов превенции осложнений. 